\title{
Pre-Service Teachers' Knowledge of Integrating Soccer and Geometry: The Case of University of Education, Winneba
}

\author{
Simon Kormla Donkor \\ University of Education, Winneba, Department of Basic Education \\ Cyril Ababio Titty \\ Institute for Distance and e-Learning, University of Education, Winneba
}

\begin{abstract}
Teacher educators play vital roles in ensuring that positive transfer of knowledge across subject areas occur. This study examined pre-service teachers' knowledge of integrating physical education and mathematics with particular focus on soccer and geometry. Using a semi-structured questionnaire, views of 145 pre-service teachers from the Department of Basic Education, University of Education, Winneba, were examined. Using descriptive statistics and One-way ANOVA, results indicated that the pre-service teachers have substantial operational but limited conceptual knowledge concerning modelling of basic geometric concepts on the field of play (soccer). The One-way ANOVA result indicated a non-statistically significant difference among the respondents' knowledge to subject preference $\left[F(2,136)=0.943, p=0.392, \eta^{2}=0.014\right]$. Among others the study recommended that tutors/lecturers expose pre-service teachers to modeling geometric concepts operationally and conceptually to facilitate their transfer of learning and their future classroom practices.
\end{abstract}

Keywords: Geometry, integration, pre-service teachers, soccer.

DOI: $10.7176 / \mathrm{JEP} / 10-14-09$

Publication date:May $31^{\text {st }} 2019$

\section{Introduction}

Physical education is an integral part of the total education process that focuses on the development of physically, mentally, emotionally and socially fit citizens through the medium of physical activities which have been carefully selected with a view to realizing these outcomes (Bucher \& Wuest, 1999). The aim of physical education, according to Kirchner and Fishburne (1995), is to produce physically educated individuals. Physical education incorporates a variety of skills and concepts that students can apply in their working life. Thus through physical education, students can develop leadership skills, values, teamwork, strategic and abstract thinking, and models. Sports like soccer as discipline in physical education is played by million players across the world making it the world's most popular sports (Dunning, 1999; Acheampong, 2018). Physical educators incorporate literacy and numeracy skills in their lesson presentations. Teaching these skills are important because 32 million adults are illiterate (Coughlan, 2015). This shows that the is a dearth of knowledge including knowledge of geometry on sports which pre-service teachers can help in disseminating the relevant aspects through their teaching in the future.

Mathematics is one of the essential areas of learning. Everyone needs to develop mathematical concepts and skills to help him/her understand its relevance and usefulness in society. The need for people to be numerate has always been identified as an important outcome. Mathematics education can contribute to the development of a broad range of numeracy skills. In an increasingly technological age the possession of problem solving and decision-making skills is an essential requisite for everyday life. Mathematics education provides students with opportunity to develop these skills and concepts to become flexible problem solvers (Curriculum Research and Development Division [CRDD], 2007).

The rationale for teaching physical education and mathematics in Ghanaian schools cannot be underestimated. The most important purpose of Physical Education is the development of mechanical efficiency i.e. coordination, awareness, relationships and skills characterized by the use of large muscles in vigorous activities featuring manipulative, locomotor and non-locomotor skills. It is for these and other reasons that access to physical education and sports activities is enshrined as a fundamental human right in the United Nations Educational, Scientific and Cultural Organization (UNESCO) Charter on Physical Education and Sports which states, inter alia, that,

every human being has a fundamental right of access to Physical Education and Sport which are essential for the full development of one's personality. The freedom to develop physical, intellectual and moral powers through physical education and Sport must be guaranteed both within the educational system and in other aspects of social life (Curriculum Research and Development Division [CRDD], 2007, p. 2; UNESCO, 1978).

Achieving these requires a sound mathematics curriculum, competent and knowledgeable teachers who can integrate instruction with assessment, classrooms with ready access to technology, and a commitment to both 
equity and excellence. The Mathematics Curriculum has been designed to provide knowledge and mathematical skills to pupils from various backgrounds and levels of ability. Today's world demands that young people should be able to use numbers competently, read and interpret numeric data, reason logically, solve problems involving calculations and mathematical reasoning, as well as communicate effectively with other people using accurate mathematical data and interpretations. That is, the curriculum emphasizes mathematical knowledge and skills that should help the young person to develop basic numeracy competence to be able to function effectively in society (Curriculum Research and Development Division [CRDD], 2007).

\section{Physical Education and Mathematics Integration}

The question is, which comes first, physical education or mathematics, as well as what dependencies there have been between the two disciplines in the past? These arguments are important in establishing the foundation, lineage, epistemology, and scope, but the interdependencies of physical education and mathematics in today's world are irrefutable. The linkages between physical education and mathematics are enormous; both are handson and hands-on classes tends to improve motivation, curiosity, achievement and discourages cramming. According to Claxton (2007), curriculum review has raised the importance of learning to learn and developing children's learning power as a goal of lifelong learning, alongside the specific applications of learning that the subjects themselves can offer.

According to McNeil (1985), curricular integration assists students to identify the links, not only between ideas and processes within a single field, but also between ideas and processes, in separate fields and in the world outside school. Participation in sports, martial arts or even dance and aerobics, is always a positive influence on a student's overall personality (Fitzgerald, 2008). Children need to explore these concepts regularly and practically in order to reinforce learning. Integration also means creating lesson plans that seamlessly integrate all components of mathematics into your physical education programme on a daily basis. Boyer (1983) wrote on the committee's behalf: "While we recognize the integrity of the disciplines, we also believe their current state of splendid isolation gives students a narrow and even skewed vision of both knowledge and the realities of the world" (pp. 114-115).

Chiappetta (2009) says that Mathematics should be integrated into the other subjects to make students think about the real world. Integration will make students start to think about why things happen, giving them a practical approach to learning and using mathematics (Chiappetta (2009). Although not always realized, mathematics plays a very important role in sports. Werra (1988) said, people think about mathematics being applied in the sciences and engineering. Yet, mathematics plays a large role in efficiency of sports. Due to the abstract nature of some concepts in mathematics, many children find learning in this subject difficult. Being able to visualize shape, space, distance and volume and then apply these concepts into practical situations can support understanding and learning. Informal observation and discussion have disclosed that many teachers approach the following mathematical concepts through physical exploration: length, distance, area, mass, angle, time, space, analysis and problem solving. Centres that were found to have a high-quality, play-based learning program incorporated: a daily schedule that included active indoor and outdoor physical play, integration of music, movement and creative expression and adult-child interactions that modelled moderate to high levels of physical activity (meaning that educators were at times as physically engaged in active play as the children) (Steglin, 2005).

Providing the opportunity for students to manipulate objects, equipment and supplies fosters interaction, comprehension and above all brings harmony in their minds. Doubts, chaos and confusions are cleared about certain notions when an integrated approach is adopted. Subject integration acts as a reinforcement tool that breaks disciplinary boundaries thereby providing the teacher with more flexibility.

\section{Soccer and Geometry Integration}

Soccer is a team sport played between two teams of eleven players with a spherical ball (Encyclopedia Britannica, 2008). It is played by 250 million players in over 200 countries and dependencies, making it the world's most popular sport (Dunning, 1999). The International Federation of Football Association (FIFA) standard dimensions of a football field should be within the range of (90-120) $\mathrm{m}$ long and (45-90) $\mathrm{m}$ wide. In kicking a ball, force, speed, rotation, curves and even shapes are observed in the game of soccer when players pass the ball to team mates. Team formation, tactics and systems can be found in various shapes, which are mathematically linked. The field of play is a geometrical figure divided into other geometrical shapes like circles, squares, trapezia, arcs among others.

Mathematical concepts of angles, perpendicular lines, parallel lines, fractions and measurements are used in preparation of the fields of play. Besides, team formation and player movements can produce other shapes like triangles of different kinds, trapezium, among others. In soccer, mathematics is visible on the ground dimensions as well as goal post size, ball size, player placements, crowd analysis, scores, team standings on the league table, and statistics in terms of number of fouls, corner kicks, ball possession and goals scored. It also includes fouls 
committed by a team and player, time calculations, record analysis, optimal angle for a throw (goal keeper), diagonal system of control, players have to decide the angle in which they have to kick the ball, distance ran by a player in a match, width of the wall and distance of the wall from the goal post while free kick is being kicked and a host of others.

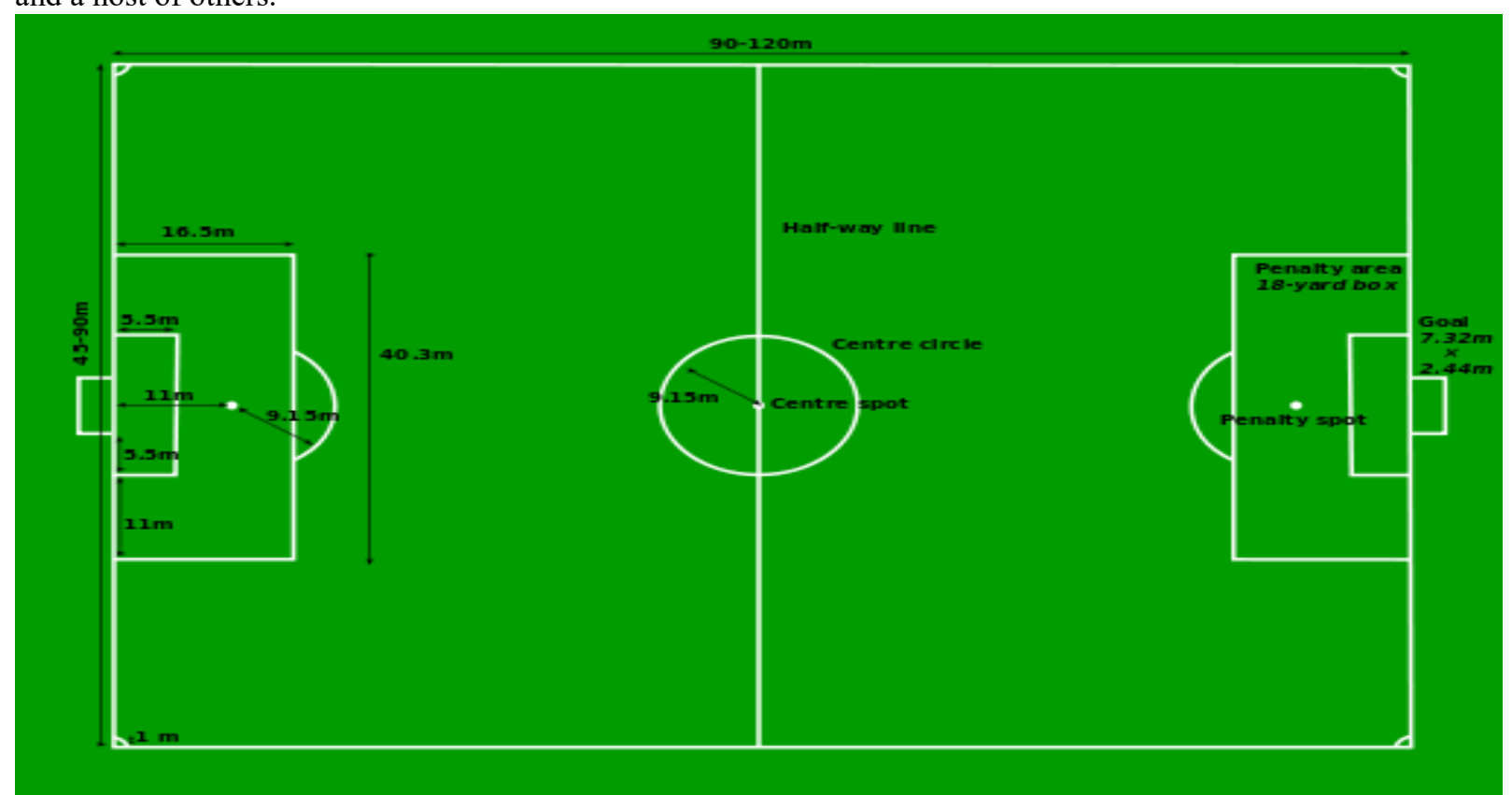

\section{Source: Robinson, (2018)}

Geometry is a branch of mathematics concerned with questions of shape, size, relative position of figures, and the properties of space. Points are considered fundamental objects in geometry. They have been defined in a variety of ways, including Euclid's definition as 'that which has no part and through the use of algebra or nested sets. In many areas of geometry, all objects are considered to be built up from points. Players position on the field of play are illustrated by points. Lines: Euclid described a line as "breadthless length" which "lies equally with respect to the points on itself" (Faber, 1983). Lines are used mostly in soccer in the determination of the offside rule (law 11) by the officiating officials and defensive players. Lines are used in the construction of field. Angles: According to Faber, (1983), a plane angle as the inclination to each other, in a plane, of two lines which meet each other, and do not lie straight with respect to each other. The way a player assumes in taking free kicks, penalty, dribbling all illustrate angles. The markings on the ground ranging from sidelines, goal lines, penalty boxes show angles as well. The bigger the angle, the more "goal" the player taking the free kick would have to score, and realistically less area that the defending wall would be able to cover.

In modern terms, an angle is the figure formed by two rays, called the sides of the angle, sharing a common endpoint, called the vertex of the angle (Sidorov, 2001). Angles are used to study polygons and triangles, as well as forming an object of study in their own right. The study of the angles of a triangle or of angles in a unit circle forms the basis of trigonometry (Gel'fand \& Saul, 2001). Curves: A curve is a one-dimensional object that may be straight (like a line) or not; curves in 2-dimensional space are called plane curves and those in 3dimensional space are called space curves (Baker, 1954). In topology, a curve is defined by a function from an interval of the real numbers to another space (Munkres, 2000). Algebraic geometry studies algebraic curves, which are defined as algebraic varieties of dimension one (Mumford, 1999). In soccer, there are curvilinear kicks where the ball travels in a straight line and curves along the way and it is usually applied when there are human walls. A sphere is a surface that can be defined parametrically. The soccer ball is spherical in shape.

Middleton and Spanias (1999), pointed to a deficiency in encouragement and classroom atmosphere for the deterioration in student attitudes and motivations towards mathematics. As students' perceptions of mathematics become more negative, they learn to dislike mathematics. The connections between mathematics and athletic competition are prominently displayed through measurable data, such as score, time, distance, etc. However, the level and types of mathematics that also exist within sports can sometimes be difficult to perceive and understand. Mathematics allows for the depictions of different models of physical motions, such as running and jumping, while considering the effects of air resistance, fatigue, duration, grade of surface, etc., by utilizing various geometric and real analysis theories (Norman, 2004). Modeling physical movements is not the only aspect of sports that mathematics can represent. It is also possible to optimize in-game strategies (Wright \& Hirotsu, 2003) and compare athletic performance (Grubb, 1998) with the assistance of mathematics. In addition to mathematics' role within actual sports, mathematics facilitates the development of schedules for athletic 
competition among many colleges using highly constrained linear programming (Van Voorhis, 2002).

Several factors have been taken into account when designing the mathematics curriculum. These are: mathematical concepts and skills, terminology and vocabulary used, and the level of proficiency of English among teachers and pupils. It is hoped that with the knowledge and skills acquired in Mathematics, pupils will discover, adapt, modify and be innovative in facing changes and future challenges. The learning of mathematics at all levels involves more than just the basic acquisition of concepts and skills. It involves most importantly, an understanding of the underlying mathematical thinking, general strategies of problem solving, communicating mathematically and inculcating positive attitudes towards an appreciation of mathematics as an important and powerful tool in everyday life.

\section{Objectives of the Study}

In other to succeed in conducting this research and appreciate the fact that the subjects we study in our educational sectors are linked to each other, the researcher sets out these objectives of the study:

1. To explore pre-service teachers' success of connecting basic geometric concepts applied in soccer.

2. To identify pre-service teachers' knowledge level in applying geometric concepts in the teaching and learning of soccer.

\section{Research Questions}

The study was guided by the following research questions:

1. What are the successful connections of basic geometric concepts in soccer by pre-service teachers?

2. What level of knowledge do pre-service teachers have in applying geometric concepts in the teaching and learning of soccer?

\section{Hypothesis}

$\mathbf{H}_{0}$ Pre-service teachers' knowledge of integrating soccer and basic geometric concept will not differ significantly with respect to their subject preference.

\section{Methodology}

The study employed a descriptive survey research design in order to collect valid and reliable data. From a target population of three hundred and ninety-four (394) level 300 pre-service teachers of the Department of Basic Education, University of Education, Winneba, one hundred and forty-five (145) were actually involved in the study. This study considered only the level 300 pre-service teachers in the 2017/2018 academic year because they are the ones who have been imbued with content and theory in both physical education and mathematics which they would be teaching after completion of B.ed Basic Education programme, hence the need to check for their knowledge in integrating them. Even though the level 400 students have also been imbued with content in both physical education and mathematics, they were excluded from the study because they were out for their internship programme.

Purposive and simple random sampling techniques were used to select the sample. A self-constructed semistructured questionnaire was used as a tool for collecting data. The open-ended part of the questionnaire provided the participants with examples of basic geometric concepts and their task was to exemplify as many of such concepts on the soccer field of play as possible. The close-ended section gave an opportunity to the participants to indicate their agreement or disagreement with some items in relation to integrating soccer and geometry as areas of study. The questionnaire was pre-tested to check its reliability and validity. The face validation was ensured by giving the questionnaire to colleague faculty members to check for any typographical errors with the various statements while that of content validation was done by giving the instrument to a Professor of Physical Education and a Senior Lecturer of Mathematics which is consistent with Borg and Gall (2003) position in achieving content validity of an instrument through expert judgement. The reliability of the instrument was approached as the internal consistencies of the various items in the questionnaire was assessed using Cronbach Alfa. The overall instrument yielded a Cronbach Alfa coefficient of 0.86 , being indicative of internal consistency as explained by Mcmillan and Schumacher (2010), that a Cronbach Alfa coefficient of at least 0.70 or higher.

\section{Data Collection Procedure and Data Analysis}

The respondents were given ample time, during one of the physical education lectures time to respond to the open-ended part first, after which the close-ended part was administered to them. This was to prevent them from transferring information from one section to the other. Summative content analysis, descriptive statistics such as simple frequency and percentages and inferential statistics such as the One-way ANOVA were used to examine the responses received from the respondents. Classifications and codifications from the open-ended section were done by the two researchers (physical education tutor and mathematics tutor). The strength of the agreement 
between the coders was calculated using the kappa coefficient. The analysis showed that the strength of agreement between the two raters was substantially strong $[\kappa=.785$ (95\% CI, 300 to .886), $p<.000)]$ (Landis \& Koch, 1977).

\section{Results}

Table 1: Demographic Characteristics of the Participants

\begin{tabular}{|c|c|c|c|}
\hline Variable & Level & Frequency & Percentage \\
\hline \multirow{2}{*}{ Gender } & Male & 92 & 63.4 \\
\hline & Female & 53 & 36.6 \\
\hline \multirow{5}{*}{ Age } & Below 18 & 1 & 0.70 \\
\hline & $18-23$ & 35 & 24.1 \\
\hline & $24-27$ & 80 & 55.2 \\
\hline & $28-33$ & 28 & 19.3 \\
\hline & $34+$ & 1 & 0.70 \\
\hline \multirow{3}{*}{ Favorite subjects } & Mathematics & 70 & 48.3 \\
\hline & Physical Education & 34 & 23.4 \\
\hline & Other Subjects & 41 & 28.3 \\
\hline \multirow{3}{*}{ Favorite Sports } & Soccer & 76 & 52.4 \\
\hline & Athletics & 45 & 31.0 \\
\hline & Other Sports & 24 & 16.6 \\
\hline
\end{tabular}

\section{Source: Field Data (2018)}

The data in Table 1 has revealed that out of the 145 participants who took part in the study, $92(63.4 \%)$ were males whereas $53(36.6 \%)$ were females. The results of the pre-service teachers' background characteristics show that their ages ranged from below 18 to 34 and above. However, majority $(n=80,55.2 \%)$ of the participants were between the ages of 24-27 years. The results further show that $70(48.3 \%)$ of the respondents' favorite subject was mathematics, $34(23.4 \%)$ of them asserted physical education was their favorite subject while the rest $(n=41,28.3 \%)$ indicated that they preferred other subjects to the two main subjects under consideration. The respondents also had the chance to indicate their preferred sporting activity and the analysis reveals that $76(52.4 \%)$ liked soccer, $45(31.0 \%)$ like athletics and $24(16.6 \%)$ liked other sporting activities.

\section{Research Question 1}

What are the successful connections of basic geometric concepts in soccer by pre-service teachers?

The first research question focused on pre-service teachers' successful connection of basic geometric concepts (point, arc/semi-circle, line segment, angles, triangle, square rectangle and circle) with self-identified examples from the field of play (soccer). Findings with respect to this research question are presented on Table 2.

The respondents were able to operationalize the various geometric concepts in a number of ways. However, some of the examples given by the respondents were not relevant and as such were not included. Others were related to each other and therefore, were amalgamated into a single model. From Table 1 for example, the concept of point was exemplified in about 15 different ways by the respondents and was condensed into 7 models, the concept of arc/semi-circle was exemplified in 13 ways and condensed into 4 models; line segment 15 way and subsumed into 5 models; angles 64 were condensed into 4 models; triangle 36 condensed into 3; square 36 condensed into 2 models; rectangle 64 condensed into 5 models and the concept circle, exemplified by the respondents in 10 different ways and it was condensed into 2 models. 
Table 2: Examples of the Geometric Concepts given on the Field of Play (Soccer)

\begin{tabular}{|c|c|c|}
\hline Geometric Concept & Example in Soccer & Frequency \\
\hline \multirow{7}{*}{ Points } & The penalty kick spot & 68 \\
\hline & The corner spot & 67 \\
\hline & The center of the field & 41 \\
\hline & Free kick spot & 18 \\
\hline & Goal kick spot & 7 \\
\hline & Throw-in spot & 4 \\
\hline & Off side kick spot & 4 \\
\hline \multirow{4}{*}{ Arc/Semi-circle } & Half of the center circle & 58 \\
\hline & Arc on the 18-yard box (penalty arc) & 40 \\
\hline & Corner arc & 26 \\
\hline & Arc of flying ball & 6 \\
\hline \multirow{5}{*}{ Line Segment } & Center line & 51 \\
\hline & Goal line & 38 \\
\hline & Throw line or side lines & 34 \\
\hline & The 18 and 6 -yard lines & 17 \\
\hline & Linear motion kicks & 13 \\
\hline \multirow{4}{*}{ Angles } & Corner kick region & 75 \\
\hline & The 18 and 6-yard box & 25 \\
\hline & Goal post (the upright and cross bar joints) & 25 \\
\hline & Center circle/center arc & 17 \\
\hline \multirow{3}{*}{ Triangle } & Player positioning (triangular passing) & 46 \\
\hline & Corner region of the field & 16 \\
\hline & When the field is divided diagonally. & 4 \\
\hline \multirow{2}{*}{ Square } & Player formation & 21 \\
\hline & Square passing & 15 \\
\hline \multirow{5}{*}{ Rectangle } & 18 and 6 yards boxes & 77 \\
\hline & Field of play (turf) & 56 \\
\hline & Goal posts & 21 \\
\hline & Player positions & 2 \\
\hline & Referees' caution cards & 2 \\
\hline \multirow{2}{*}{ Circle } & Center circle & 128 \\
\hline & Circular formation for prayers & 1 \\
\hline
\end{tabular}

\section{Source: Field Data (2018)}

From Table 2, the data show examples given by the respondents in relation to the concept of point on the field of play in soccer were: the penalty kick spot (frequency $[f]=68)$, the corner spot $(f=67)$, the center of the field $(f=41)$, the free kick spot $(f=18)$, the goal kick spot $(f=7)$, the throw-in spot $(f=4)$ and the off-side kick spot $(f=4)$. Some of the misrepresentation of the concept stated by the participants during the study were "indirect point", "goal post", "18-yard box", 16-yard box point" among others. Models representing arc/semicircle were given by the participants and they ranged from, half of the center circle $(f=58)$ to arc on the 18-yard box (penalty arc) $(f=40)$ to corner arc $(f=26)$ and finally to arc of a flying ball $(f=6)$.

An examination of findings related to line segment indicated that examples such as center line $(f=51)$, goal line $(f=38)$, throw line or side line $(f=34)$, the 18 and 6-yard lines and the liner motion kicks by player $(f=13)$. When the angle models were examined as presented in Table 2 , it could be observed that the pre-service teachers indicated corner kick region $(f=75)$, the various angles in the 18 and the 6 -yard box $(f=25)$, the various angles found in the goal post structure $(f=25)$, and center circle/center arc $(f=17)$ as examples of angles found on the field of play. With regards to the triangle models, pre-service teachers were asked to exemplify the geometric concept on the field of play. They indicated player positioning $(f=46)$, corner region of the field $(f=16)$ and dividing the field diagonally $(f=4)$. A participant however, expressed the idea of not being able to model the 
concept of triangle by stating "none".

As seen in Table 2, the respondents illustrated the term square, rectangle and circle in various models. The concept square was modeled in the form of player formation $(f=21)$ and square passing $(f=15)$ whilst that of rectangle was modeled in the form of the 18 and 6-yards boxes $(f=77)$, the shape of the field of play $(f=56)$, the goal post $(f=21)$, player positions $(f=2)$ and referees' caution cards $(f=2)$. And the circle was also modeled in the form of center circle $(f=128)$ and Circular formation for prayers before start and restart of the game $(f=$ 1). In the case of the circle, some of the misrepresentation of the concept stated by the participants during the study were, "Football or the ball" (sphere), "The nature of how spectators sit around the field" (oval) and "Athletics tracks around the field of play" (oval).

\section{Research Question 2}

What level of knowledge do pre-service teachers have in applying geometric concepts in the teaching and learning of soccer?

The pre-service teachers were given the opportunity to indicate their level of agreement or disagreement on 12 items on the application of some basic geometric concepts to soccer. This was to help describe their knowledge level in applying geometric concepts in a hypothetical teaching and learning of soccer situation. Descriptive statistics (mean and standard deviation) were used to analyze the data. Mean rating of 1.0-2.4 represents below average knowledge, 2.5 represents average knowledge and 2.6-4.0 represents above average knowledge. This criterion of mean analysis was used by Shamsid-Deen and Smith (2006). The result of the analysis is presented in Table 3 .

\section{Table 3: Application of some Basic Geometric Concepts to Soccer}

\begin{tabular}{llll}
\hline & Statement & $\boldsymbol{M}$ & $\boldsymbol{S D}$ \\
\hline $\mathbf{1}$ & Ball trajectory could be linear and curve-linear motions & 3.35 & 0.6 \\
$\mathbf{2}$ & Lines are used in the construction of a soccer field & 3.77 & 0.4 \\
$\mathbf{3}$ & Points are used in the construction of a soccer field & 3.67 & 0.5 \\
$\mathbf{4}$ & The concept of angles is explored in soccer & 3.65 & 0.5 \\
$\mathbf{5}$ & There are geometrical shapes on the field of play & 3.63 & 0.6 \\
$\mathbf{6}$ & Pythagoras theorem is employed in construction of angles on the field & 3.37 & 0.7 \\
$\mathbf{7}$ & Player movement during play create different geometrical figures & 3.54 & 0.6 \\
$\mathbf{8}$ & The concept of polygon is sometimes used in the manufacturing of soccer balls & 3.19 & 0.9 \\
$\mathbf{9}$ & The concept of angles is explored by goalkeepers in preventing goals from being scored & 3.50 & 0.7 \\
$\mathbf{1 0}$ & Players take kicks from specific spots/points toward intended angles and directions & 3.68 & 0.6 \\
$\mathbf{1 1}$ & Lines and points are used by referees in calling for offside during play & 3.69 & 0.5 \\
$\mathbf{1 2}$ & The concept matching is utilized during play & 3.48 & 0.5 \\
\hline
\end{tabular}

Source: Field Data (2018); Key: $M=$ Mean and $S D=$ Standard Deviation

An examination of Table 3 indicates that most of the respondents' knowledge level on the application of the identified basic geometric concepts to soccer was above average. This observation was made because the mean scores on all the items were far above the average knowledge score $(M=2.5)$. For example, results as presented in Table 3 reveal that from all the items, pre-service teacher rated "Lines are used in the construction of a soccer field" highest $(M=3.77, S D=0.4)$ while "The concept of polygon is sometimes used in the manufacturing of soccer balls" was rated the lowest $(M=3.19, S D=0.9)$. This result from the analysis suggests that the preservice teachers who took part in this study have adequate knowledge on the application of the explored basic geometric concepts to soccer to teach their future learners. They have, therefore, adequate knowledge and competence to teach and integrate these two bodies of learning.

\section{Testing of Hypothesis}

$\mathbf{H}_{\mathbf{0}}$ Pre-service teachers' knowledge of integrating soccer and basic geometric concept will not differ significantly with respect to subject preference.

A One-Way ANOVA test was conducted on the data with the aim of evaluating if subject preference was a significant differentiator of pre-services teachers' knowledge level in applying basic geometric concepts to soccer or not. The mean scores on the various subject preference reported by the pre-service teachers were very high; mathematics $(M=42.3, S D=3.6, n=67)$, physical education $(M=43.3, S D=3.3, n=32)$ and other subjects $(M=42.5, S D=3.0, n=40)$. On the face value, an examination of the mean scores presented indicates that some amount of difference exists. It indicated that pre-service teachers with preference for physical education had the highest mean score. To establish if the differences were statistically significant, a One-Way ANOVA test was conducted. The test of homogeneity was not significant, Levene test $-F(2,136)=0.943, \mathrm{p}=$ 0.392 , for pre-service teachers' knowledge level scale. The analysis indicated that the homogeneity of variance 
assumption underlying the application of ANOVA was tenable on the data. The result of the ANOVA test is presented in Table 4.

Table 4: One-Way ANOVA

\begin{tabular}{llllll}
\hline & Sum of Squares & Df & Mean Square & $F$ & Sig. \\
\hline Between Groups & 21.382 & 2 & 10.691 & 0.943 & 0.392 \\
Within Groups & 1541.064 & 136 & 11.331 & & \\
Total & 1562.446 & 138 & & & \\
\hline
\end{tabular}

The analysis as presented in Table 4 indicates that the ANOVA result was not significant $[F(2,136)=$ $0.943, p=0.392]$. Another analysis of importance which was considered by the researchers was the effect size, in this case the eta squared $\left(\eta^{2}\right)$. The effect size statistics provide an indication of the magnitude of the differences among groups. There are a number of different effect size statistics. The one used here is the Eta squared $\left(\eta^{2}\right)$. It is important to note that Eta squared range from 0-1 (Cohen, 1988). For the current study, the findings did not show a statistically significant result, and the difference in the mean scores of the groups was very small $(42.3,43.3$ and 42.5$)$. This is evident in the small effect size obtained $\left(\eta^{2}=0.014\right)$.

\section{Discussion}

The findings of the study revealed that the pre-service teachers had substantial knowledge about integrating soccer and basic geometry. The results obtained do not support the assertion that pre-service teachers are deficient in integrating geometry and soccer. For example, the result obtained does not support the idea of a deficiency in pre-service teachers' content knowledge of geometry and pedagogy in integrating soccer and geometry as suggested by Pirasa, (2016). Ginsburg (2008), examined high school mathematics teachers' abilities of connecting mathematics with daily life, also does not lend support to this finding. In Gainsburg's view, although a large number of the teachers' real life examples can be counted, it has been determined that the connections done through these examples were minimal and summarized, and that there was not an ability to motivate and canalize the students to think. The results were however, related to Phillips and Marttinen (2013), Finn and McInnis (2014) and Kokko, Eronen and Sormunen (2015) who found that cross-curricular integration is successful in an array of disciplines. And again confirms, Eli (2009) (as cited by Pirasa, 2016) assertion that the knowledge of pre-service mathematics teachers for geometry instruction was at a low level and that the mathematical connection carried out was a lot more operational rather than being conceptual.

\section{Conclusion and Recommendations}

The love for Physical Education and Mathematics or otherwise are instilled at school and as such what teachers do as well as how they do it, is considered absolutely critical to the future of inter-disciplinary teaching. In conclusion, the findings reveal the importance of pre-service teachers possessing the adequate knowledge of integrating Physical Education (soccer) and Mathematics (geometry); however, some of the models exemplified by the respondents were inaccurate. In this research, most pre-service teachers were able to operationally demonstrate the ability of integrating basic geometric concepts such as point, line segment, square, rectangle, triangle among others to models on the soccer (field of play) rather than conceptually. It is also noteworthy to state that when Table 2 is examined, we can see that the participants were able to establish multiple (more than one) connections between the basic geometric concepts and soccer field play. Participants' ability to establish different connections and to eliminate the gap between school mathematics and real life is depending on how much they could transfer their classroom mathematical knowledge to the real life. For that reason, teachers of pre-service teacher have great responsibility.

Based on the findings of this study it is recommended that tutors expose pre-service teachers to modeling geometric concepts operationally and conceptually to facilitate their transfer of learning and their future classroom practices. Again, teacher training institutions should establish and develop teachers' confidence, knowledge and skills to deliver these connections effectively and apply pedagogical principles that underpin practice for both subjects. They should also ensure that adequate teaching and learning resources be made available to move away from abstract thinking to a real life practical experience. Resource centers, therefore, should be developed with charts showing mathematical concepts applied in physical education together with other teaching aids in schools.

\section{REFERENCES}

Acheampong, E.Y. (2018). How does professional football status challenge African players' behaviour? Sports and Society, Routledge Taylor \& Francis Group.

Baker, H. F. (1954). Principles of geometry. CUP Archive, 2,

Borg, W. R., \& Gall, M. D. (2003). Educational research: An introduction (5th ed.). New York: Longman.

Boyer, E. L. (1983). High school: A report on secondary education in America. New York: Harper Colophon. 
Bucher, C. (1972). Foundations of Physical Education. St. Louis: The CV Mosby Company.

Bucher, C., \& Wuest. (1999). Foundations of Physical Education and Sports. USA: Mcgraw-Hill Companies, Inc.

Chiappetta, C. (2009). Why is it Important to Integrate Mathematics with other Subjects? www.k12 academics.com

Claxton, G, (2007). Expanding Young Peoples Capacity to Learn. British Journal of Education, 55, (2), pp.115134.

Cohen, J. (1988) Statistical Power Analysis for the Behavioral Sciences. Hillsdale, NJ: Erlbaum.

Coughlan, S. (2015). Campaign warns $11 \%$ of world illiterate. BBC News. Retrieved from http://www.bbc.co.uk/news/ education-34384669

Curriculum Research and Development Division (CRDD) (2007). Mathematics teaching syllabus for primary school. Accra, Ghana

Curriculum Research and Development Division (CRDD) (2007). Physical Education teaching syllabus for primary school. Accra, Ghana

Dunning, E. (1999). The development of soccer as a world game. Sport Matters: Sociological Studies of Sport, Violence and Civilization. London: Routledge.

Faber, R. L. (1983). Foundations of Euclidean and Non-Euclidean Geometry. New York: Marcel Dekker. ISBN 0-8247-1748-1.

FIFA official laws and regulations. http://www.fifa.com/aboutfifa/officialdocuments/doclists/ laws.html

Finn, K. E., \& McInnis, K. J. (2014). Teachers' and students' perceptions of the active science curriculum: Incorporating physical activity into middle school science classrooms. Physical Educator, 71, 234-253.

Fitzgerald, J. K. (2010). Importance of Physical Education.www.buzzle.com/articles

Gainsburg, J. (2008). Real-world connections in secondary mathematics teaching. Journal of Mathematics Teacher Education, 11, 199-219. doi:10.1007/s10857-007-9070-8

Grubb, H. J. (1998). Models for comparing athletic performances. The Statistician, 47(3), 509- 521.

Kirchner, G., \& Fishburne. (1995). Physical Education for Elementary School Children. Madison: Brown and Benchmark Publishers.

Kokko, S., Eronen, L., \& Sormunen, K. (2015). Crafting maths: Exploring mathematics learning through crafts. Design \& Technology Education, 20(2), 22-31.

Landis J. R, \& Koch G. G. (1977). An application of hierarchical kappa-type statistics in the assessment of majority agreement among multiple observers. Biometrics 33: 363-374.

Landis, J. R., \& Koch, G. G. (1977). The Measurement of Observer Agreement for Categorical Data. Biometrics, $33(1), 159-174$

McMillan, J. H., \& Schumacher, S. (2010). Research in education: Evidence-Based Inquiry (7 ${ }^{\text {th }}$ Ed.). Boston, MA: Pearson.

McNeil, J. D. (1985). Curriculum-A comprehensive introduction. Toronto, ON: Little Brown

Middleton, J. A., \& Spanias, P. A. (1999). Motivation for Achievement in Mathematics: Findings, Generalizations, and Criticisms of the Research. Journal for Research in Mathematics Education , 30 (1), 65-88.

Mumford, D (1999). The Red Book of Varieties and Schemes, volume 1358 of Lecture Notes in Mathematics. Springer-Verlag, Berlin.

Mumford, D. (1999). The Red Book of Varieties and Schemes Includes the Michigan Lectures on Curves and Their Jacobians (2nd ed.). Springer-Verlag.

Munkres, J. R. (2000). Topology. Vol. 2. Upper Saddle River: Prentice Hall.

Norman, J. M. (2004). Running uphill: Energy needs and Naismith's rule. The Journal of the Operational Research Society, 55(3).

Phillips, S., \& Marttinen, R. (2013). Physical education and maths: The perfect couple. New Zealand Physical Educator, 46(3), 20.

Pirasa, N. (2016). The connection competencies of pre-service mathematics teachers about geometric concepts to daily-life. Universal Journal of Educational Research, 4(12), 2840-2851. https://doi.org/10.13189/ujer.2016.041218

Robinson, J. (2018). Parts of the soccer field. Accessed from https://www.thoughtco.com/soccer-the-field3557664

Shamsid-Deen, I., \& Smith, B. P. (2006). Integrating contextual teaching and learning practices into the family and consumer sciences teachers' curriculum. Journal of Family and Consumer Sciences Education, 24(1), 14-27.

Sidorov, L.A. (2001) [1994], "Angle", in Hazewinkel, Michiel, Encyclopedia of Mathematics, Springer Science+Business Media B.V. / Kluwer Academic Publishers, ISBN 978-1-55608-010-4

Sidorov, L.A. (2001), "Angle", in Hazewinkel, Michiel, Encyclopedia of Mathematics, Springer Science 
Business Media B.V. / Kluwer Academic Publishers, ISBN 978-1-55608-010-4

Steglin, D. A. (2005). Making the case for play policy: Research-based reasons to support play-based environments. Young Children, 60(2), 76-86.

UNESCO (1978). International Charter of Physical Education and Sport, www.unesco.org/educatioAn/educprog/eps/EPSanglais/EVENTS_ANG/international_charter_ang.htm July, 2018.

Van Voorhis, T. (2002). Highly constrained college basketball scheduling. The Journal of the Operational Research Society, 53(6), 603-609.

Werra, D. (1988). Scheduling Sports Competitions: Discrete Applied Mathematics, Amsterdam: Elsevier Science.

Wright, M., \& Hirotsu, N. (2003). The professional foul in football: Tactics and deterrents. The Journal of the Operational Research Society, 54(3), 213-221. 